\title{
Effect of Filler-Filler Interactions on Mechanical Properties of Phenol Formaldehyde Based Hybrid Composites
}

\author{
Bharath Basavaraj Pattanashetty ${ }^{1 \mathrm{a}}$, Suresha Bheemappa ${ }^{2 \mathrm{~b}^{*}}$ \\ and Hemanth Rajashekaraiah ${ }^{3 c}$
}

\author{
${ }^{1}$ Department of Automobile Engineering, Sri Jagadguru Mallikarjuna Murugharajendra \\ Institute of Technology, Chitradurga - 577 502, Karnataka, India \\ ${ }^{2}$ Department of Mechanical Engineering, The National Institute of Engineering, Mysore - 570008 , \\ Karnataka, India \\ ${ }^{3}$ Department of Mechanical Engineering NIE Institute of Technology, Mysore - 570018 , \\ Karnataka, India \\ abharathauto999@gmail.com, ${ }^{\text {b }}$ sureshab2004@yahoo.co.in, chemanth@nieit.ac.in
}

Keywords: PF based hybrid composites, reinforcing fillers, and mechanical properties

\begin{abstract}
Mechanical properties of phenol formaldehyde (PF) based hybrid composites reinforced with molybdenum disulphide (molykote; $\mathrm{MC}$ ), copper $(\mathrm{Cu})$, graphite $(\mathrm{Gr})$ and antimony (Aty) particles in micron size, having different shape and aspect ratio, are studied. Incorporation of MC, $\mathrm{Cu}$ and $\mathrm{Gr}$ enhanced the hardness, compression and flexural properties of PF based hybrid composites. A slight decrease in density was observed in $\mathrm{MC}+\mathrm{Gr}$ (A5) reinforced PF based hybrid composites, making these composites suitable in weight susceptible applications. The investigations showed that the control sample A1 without $\mathrm{MC} / \mathrm{Cu} / \mathrm{Gr} /$ antimony (control sample) exhibited poorer mechanical properties. Addition of $\mathrm{Cu}, \mathrm{MC}$ and $\mathrm{Gr}$ to the control sample resulted in moderate improvement in the mechanical properties. However, hybridization of the control sample with $\mathrm{Gr}+$ Aty (A6) showed lower mechanical properties compared to that of composites filled with MC and Gr (A4 and A2) respectively. This decrease was ascribed to the tendency of non-uniform dispersion, deprived bonding of Aty particles as well as poor filler-matrix adhesion. When Aty was replaced with Gr + MC (Sample A5), filler-filler with matrix interaction appears to be increased, resulting in increased strength and modulus. The developed PF based hybrid composites have exhibited improved mechanical properties and these composites with detailed thermal and tribostudies may be recommended for railway braking applications.
\end{abstract}

\section{Introduction}

Polymeric materials with apt filler/matrix interaction and suitable fiber together with new methods to develop hybrid and multiphase polymer matrix composites (PMCs) is having prospective applications in automotive, aerospace and constructions industries. To cope with the obvious limitations of polymers, for example, low stiffness and low strength, and to expand their applications in different sectors, inorganic particulate fillers, such as micro-/nano-SiO $\mathrm{S}_{2}$, glass, $\mathrm{Al}_{2} \mathrm{O}_{3}, \mathrm{Mg}(\mathrm{OH})_{2}$ and $\mathrm{CaCO}_{3}$ particles, carbon nano tubes (CNTs) and layered silicates, are often added to develop newer PMCs, which normally combine the advantages of their constituent phases [1-3]. Particulate fillers modify the physical and mechanical properties of PMCs in many ways [4]. Among them one of the methods to use multi ingredient and multiphase polymer systems is related to controlling the physical and chemical interactions at the interface to improve the mechanical properties.

Phenolic formaldehyde (PF) resins possess exceptional bonding properties and have high stiffness, dimensional stability, outstanding heat and fire resistance due to a highly cross linked aromatic structure [5]. The major drawbacks of the PF resins which prevents its widespread applications are high brittleness and shrinkage. This properties are surmounted by inclusion of micron sized particulate fillers and load bearing synthetic fibers or elastomeric materials [6-11]. $\mathrm{PF}$ resin generates chemical bonding with synthetic fibers/surface modified fillers, leading to strong 
forces between fiber/particulate and resin. Thus, a high compatibility in the system between synthetic fiber/filler with PF resin is achieved. It is reported that copper, graphite/CNTs/carbon fiber is a potential reinforcement for phenolic resins [12-15].

Especially in automotive brakes and clutches, Non-asbestos organic (NAO) based friction materials are used, which are essentially multi ingredient systems (containing more than 10 ingredients, in general) in order to achieve the desired amalgam of performance properties [16-20].

The four categories of ingredients, viz. binders, fibers, friction modifiers and fillers based on the major function they perform apart from contributing towards friction and wear performance are selected. Binders mainly from phenolic or modified phenolic provide mechanical integrity to the friction material while fibers, such as mineral, ceramics, organic and metallic types provide mainly the strength. Friction modifiers, such as abrasives and solid lubricants are used to achieve the desired range of friction. Fillers the fourth class is again subdivided as functional fillers (to enhance the specific function, such as resistance to fade, thermal conductivity, etc.) and space fillers/inert fillers (just to cut the cost without any adverse effect on performance properties) [21]. Each of these ingredients is contributing their part to synergistic effect; however properties imbibed by particular ingredient may affect properties of other ingredients which in turn determine total synergistic effect.

To the best of our knowledge, although investigations on PF based hybrid composites have been conducted so far by several researchers, evidences of the overall effect conferred by microsize copper, molybdenum disulphide and graphite incorporation on physico-mechanical of PF based composite in any previous study are relatively scarce [22-26]. The mixture of PF, binders and fillers has been pulverized for $45 \mathrm{~min}$ to have a better dispersion of the fillers into PF and other binders. Such kind of pulverization is not usually followed during PF based multiphase composite fabrication. Generally, addition of functional fillers can provide PF with specific properties but sometimes triggers problems such as loss of some mechanical properties, degradation of the polymer matrix, etc., aspects that need to be taken care when considered for braking applications.

Based on the above cited literature, effects of different micro-sized fillers to PF based multiphase composite for disclosing microstructure and mechanical properties relationship of the resulting composites is of high interest and is the main aim of this investigation. It is expected that molykote and/graphite filled PF based hybrid composites can enable superior mechanical properties.

\section{Materials and Methods}

\subsection{Materials}

Phenol formaldehyde (PF, containing 9.2 wt. \% hexamethylenetetramine) powder with the average particle size of $35 \mu \mathrm{m}$, was considered as primary binding material along with the other secondary binding elements such as cashew nut oil, fire clay (average particle size of $200 \mu \mathrm{m}$ ), linseed oil and plaster of Paris (average particle size of $30 \mu \mathrm{m}$ ) are used to enhance the binding effect with the fillers. Friction dust (average particle size of $15 \mu \mathrm{m}$ ), rubber powder (average particle size of $18 \mu \mathrm{m}$ ) and hexamine (average particle size of $35 \mu \mathrm{m}$ ) are used as fillers, which improves the manufacturability resulting in reduction of cost. Molybdenum disulfide, a lubricating filler commercially known as Molykote (MC) with average particulate size of $50 \mu \mathrm{m}$, copper $(\mathrm{Cu})$, graphite $(\mathrm{Gr})$ and antimony (Aty) all in powder form with corresponding average particulate size of $25 \mu \mathrm{m}, 50 \mu \mathrm{m}$ and $135 \mu \mathrm{m}$ are selected as primary frictional additives. Further, ferrosilicon, barium sulphate, silicon carbide, and carbon in powder form with corresponding average particulate size of $18 \mu \mathrm{m}, 10 \mu \mathrm{m}, 25 \mu \mathrm{m}$ and $20 \mu \mathrm{m}$ are used as secondary frictional additives. They are used to reduce the wear and to improve the coefficient of friction. Short glass fiber with average diameter and length of $10 \mu \mathrm{m}$ and $6 \mathrm{~mm}$ were used as reinforcing element to improve strength and friction performance in the present investigation. Table 2 presents the role of ingredients in the intended composites. 
The source and the selected properties of the materials used to prepare the brake composites in the present investigation are listed in Table 1.

Table 1. Materials used in the Present Investigation.

\begin{tabular}{|c|c|c|c|}
\hline $\begin{array}{l}\text { Sl. } \\
\text { No. }\end{array}$ & Polymer/Filler & $\begin{array}{l}\text { Density } \\
\left(\mathrm{g} / \mathrm{cm}^{3}\right)\end{array}$ & Suppliers \\
\hline 01 & PF Powder & 1.05 & \multirow[t]{4}{*}{ Claro India Pvt. Ltd, Chennai } \\
\hline 02 & Barium sulphate & 4.48 & \\
\hline 03 & Antimony & 6.68 & \\
\hline 04 & Hexamine & 1.33 & \\
\hline 05 & Cashew nut oil & 0.95 & \multirow{3}{*}{$\begin{array}{l}\text { Sathya Cashew Chemical Ltd, Chennai, } \\
\text { India }\end{array}$} \\
\hline 06 & Friction dust & 0.45 & \\
\hline 07 & Linseed oil & 0.93 & \\
\hline 08 & Fire clay & 2.40 & \multirow[t]{4}{*}{ Mysore Pure Chemicals, Mysuru, India. } \\
\hline 09 & Rubber powder & 0.91 & \\
\hline 10 & Molykote & 4.80 & \\
\hline 11 & Carbon powder & 1.80 & \\
\hline 12 & Plaster of Paris & 2.70 & Murugan Hardware, Erode, India \\
\hline 13 & Ferrosilicon & 2.34 & Kumar Hardware, Coimbatore, India \\
\hline 14 & Copper powder & 8.90 & $\begin{array}{l}\text { Metal Powder Company (MEPCO) } \\
\text { India PVT Ltd, Sivakasi, India }\end{array}$ \\
\hline 15 & Graphite & 2.26 & Gowtham Chemicals, Chennai, India \\
\hline 16 & Silicon carbide & 3.20 & $\begin{array}{l}\text { Carborundum Universal Ltd (CUMI), } \\
\text { Cochin, India }\end{array}$ \\
\hline 17 & Fiber glass & 2.54 & $\begin{array}{l}\text { Mukthagiri Industrial Corporation, } \\
\text { Mumbai, India }\end{array}$ \\
\hline
\end{tabular}

Table 2. The ingredients and their role in the composites [27].

\begin{tabular}{|c|c|c|}
\hline Sl. No. & Description of Material & Role in the composition \\
\hline 1. & Phenol Formaldehyde & $\begin{array}{l}\text { This is a derivative of Phenolic resin and available in } \\
\text { powder form. It is used for binding all the other } \\
\text { ingredients as solid piece at elevated temperature. This } \\
\text { powder melts and flow freely in between the granular } \\
\text { structure of the fillers at } 128{ }^{\circ} \mathrm{C} \text { and integrates the } \\
\text { composite mixture into one homogeneous block taking } \\
\text { the required shape of the die. } \\
\text { - Withstand high temperature. } \\
\text { - Wear resistant. }\end{array}$ \\
\hline 2. & Barium sulphate & $\begin{array}{l}\text { - Wear resistant. } \\
\text { - High thermal stability. }\end{array}$ \\
\hline 3. & Antimony & $\begin{array}{l}\text { It is an inert material (metal), available in powder form. } \\
\text { - Improving the density. } \\
\text { - Dissipating the frictional heat generated on account of } \\
\text { braking. } \\
\text { - Providing bearing characteristic. } \\
\text { - Providing anti-wear properties. }\end{array}$ \\
\hline 4. & Hexamine & $\begin{array}{l}\text { - Acts as a catalyst and speed up polymerization. } \\
\text { - Improve hardness of brake blocks. }\end{array}$ \\
\hline 5. & Cashew Nut Shell oil & $\begin{array}{l}\text { It is derived from cashew nut shell, used as a binder and } \\
\text { friction modifier. It also possess good refractoriness, } \\
\text { which can withstand up to } 400{ }^{\circ} \mathrm{C} \text {. }\end{array}$ \\
\hline
\end{tabular}




\begin{tabular}{|c|c|c|}
\hline 6. & Cashew Friction Dust & $\begin{array}{l}\text { It is derived from cashew nut shell, and has the following } \\
\text { characteristics. } \\
\text { - Mould ability. } \\
\text { - Good friction properties. } \\
\text { - Refractoriness i.e. to withstand elevated temperature. } \\
\text { - Environment friendly. }\end{array}$ \\
\hline 7. & Linseed oil & Natural oil used as an additive for improving bonding. \\
\hline 8. & Fire Clay & $\begin{array}{l}\text { This is used as a filler for providing adequate frictional } \\
\text { characteristics. }\end{array}$ \\
\hline 9. & Rubber Powder & $\begin{array}{l}\text { This is added in granular form to facilitate wear resistance } \\
\text { and improves cushioning properties to withstand the } \\
\text { impact during braking. }\end{array}$ \\
\hline 10. & Molykote & $\begin{array}{l}\text { As a solid lubricant additive in brake lining applications } \\
\text { - Excellent lubricating properties } \\
\text { - Reduction of friction and wear } \\
\text { - Resistant to oxidation } \\
\text { - Extreme pressure resistance. } \\
\text { - Wide service temperature range. }\end{array}$ \\
\hline 11. & Carbon Powder & It is used as hardener. \\
\hline 12. & Plaster Of Paris & $\begin{array}{l}\text { It is used a filler and benefitted with good mould ability, } \\
\text { refractoriness and improves the mechanical properties like } \\
\text { density and crushing strength. }\end{array}$ \\
\hline 13. & Ferrosilicon & $\begin{array}{l}\text { A metallic compound of iron and silicon, and helps in } \\
\text { improving the non-sticking characteristic at elevated } \\
\text { temperature, density and compactness. }\end{array}$ \\
\hline 14. & Copper powder & $\begin{array}{l}\text { It reduces wear and prevent scoring, possess high thermal } \\
\text { conductivity and forms uniform frictional film. }\end{array}$ \\
\hline 15. & Graphite Powder & $\begin{array}{l}\text { This, when combined with rubber gives the brake block, a } \\
\text { smooth surface in order to give maximum bedding of the } \\
\text { brake blocks. It also possesses anti-sticking properties and } \\
\text { stabilizes coefficient of friction }(\mu) \text {. }\end{array}$ \\
\hline 16. & Silicon carbide & $\begin{array}{l}\text { It possess high hardness, strength, good chemical and } \\
\text { thermal stability, high melting point, oxidation resistance } \\
\text { and high wear resistance. }\end{array}$ \\
\hline 17. & Fiber Glass & They are used as reinforcements for the composites. \\
\hline
\end{tabular}

\subsection{Methods}

2.2.1. Composite Fabrication: The Phenol Formaldehyde (PF) multi phased composite samples were prepared by hot compression moulding technique. The various PF composites, their ingredients and proportions are presented in Table 3. The process includes mixing, hydraulic pressing, curing and post curing. Initially the particulate fillers were mixed using mechanical plough type shear mixer followed by the addition of fibers to ensure homogeneous distribution. The mould was preheated to $80{ }^{\circ} \mathrm{C}$. Hardening of the composite made of several different materials is referred as curing. This can be achieved by heating, chemical additive or ultraviolet radiation. To relieve the frozen-in stress and cure the residual resin post curing is done. This method also increases heat resistance, better chemical and mechanical properties and cross link of the polymer. The mixture was filled into the mould cavity and closed hydraulically at a temperature of $135^{\circ} \mathrm{C}$ and load of 50 tonnes for $40 \mathrm{~min}$, with three intermittent breathings were given in between to expel the volatile gases. The test samples were prepared as per ASTM standards. 
Table 3. Constituents of the phenol formaldehyde hybrid composites for the present study.

\begin{tabular}{|c|c|c|c|c|c|c|}
\hline \multirow[b]{2}{*}{ Composites $^{*}$} & \multicolumn{6}{|c|}{ Composite Constituents } \\
\hline & $\begin{array}{l}\text { Binders } \\
\text { (wt. \%) }\end{array}$ & $\begin{array}{l}\text { Fillers } \\
\text { (wt. \%) }\end{array}$ & $\begin{array}{c}\text { Molykote } \\
\text { (wt. \%) }\end{array}$ & $\begin{array}{l}\text { Copper } \\
\text { (wt. \%) }\end{array}$ & $\begin{array}{c}\text { Graphite } \\
\text { (wt. \%) }\end{array}$ & $\begin{array}{c}\text { Antimony } \\
\text { (wt. \%) }\end{array}$ \\
\hline $\mathrm{A} 1=\mathrm{B}+\mathrm{F}$ & $60^{\wedge}$ & $40^{\$}$ & -- & -- & -- & -- \\
\hline $\mathrm{A} 2=\mathrm{B}+\mathrm{F}+\mathrm{MC}$ & 55 & 40 & 05 & --- & $-\overline{---}$ & --- \\
\hline $\mathrm{A} 3=\mathrm{B}+\mathrm{F}+\mathrm{Cu}$ & 55 & 40 & --- & 05 & --- & --- \\
\hline $\mathrm{A} 4=\mathrm{B}+\mathrm{F}+\mathrm{Gr}$ & 55 & 40 & --- & --- & 05 & --- \\
\hline $\mathrm{A} 5=\mathrm{B}+\mathrm{F}+(\mathrm{Gr}+\mathrm{MC})$ & 55 & 40 & 2.5 & --- & 2.5 & --- \\
\hline $\mathrm{A} 6=\mathrm{B}+\mathrm{F}+(\mathrm{Gr}+\mathrm{Aty})$ & 55 & 40 & --- & --- & 2.5 & 2.5 \\
\hline $\begin{array}{l}\text { "B }- \text { Phenol formaldehy } \\
\text { ^Binders includes PF Powde } \\
\text { Rubber powder 02 } \\
\text { \$Common fillers include }\end{array}$ & $\begin{array}{r}\text { and other } \\
\mathrm{Cu}-\mathrm{Co} \\
30 \text { wt. } \%+ \\
\%+\text { Hexam } \\
\text { Ferrosilicon } \\
\text { Fiber gla }\end{array}$ & $\begin{array}{l}\text { nders as list } \\
\text { per, } \mathrm{Gr}-\mathrm{G} \\
\text { ashew nut o } \\
\text { he } 01 \text { wt. \% } \\
5 \text { wt. } \%+\mathrm{E} \\
02 \text { wt. } \%+\end{array}$ & $\begin{array}{l}\mathrm{d} \text { below, } \mathrm{F}-\mathrm{f} \\
\text { phite, Aty }-A \\
10 \text { wt. \% }+\mathrm{F} \\
\text { - Linseed oil } 0 \\
\text { arium sulphate } \\
\text { Carbon powde }\end{array}$ & $\begin{array}{l}\text { lers as listec } \\
\text { timony } \\
\text { clay10 wt. } \\
\text { wt. } \%+\mathrm{Pl} \\
10 \text { wt. } \%+ \\
01 \text { wt. } \%\end{array}$ & $\begin{array}{l}\text { elow, MC - I } \\
+ \text { Friction du } \\
\text { er of Paris } 01 \\
\text { icon carbide } 0\end{array}$ & $\begin{array}{l}\text { lykote, } \\
05 \text { wt. \% + } \\
\text { t. } \% \\
\text { wt. } \%+\end{array}$ \\
\hline
\end{tabular}

The flow chart in Fig. 1 reveals the major stages of preparation of PF based composites. Multi phased PF composites (A2, A3, A4, A5 and A6) comprising of molykote, copper, graphite and antimony possess $5 \mathrm{wt}$ \% of fireclay reducing the binder content from $60 \mathrm{wt}$ \% in former (i.e. A1) to 55 wt. $\%$.

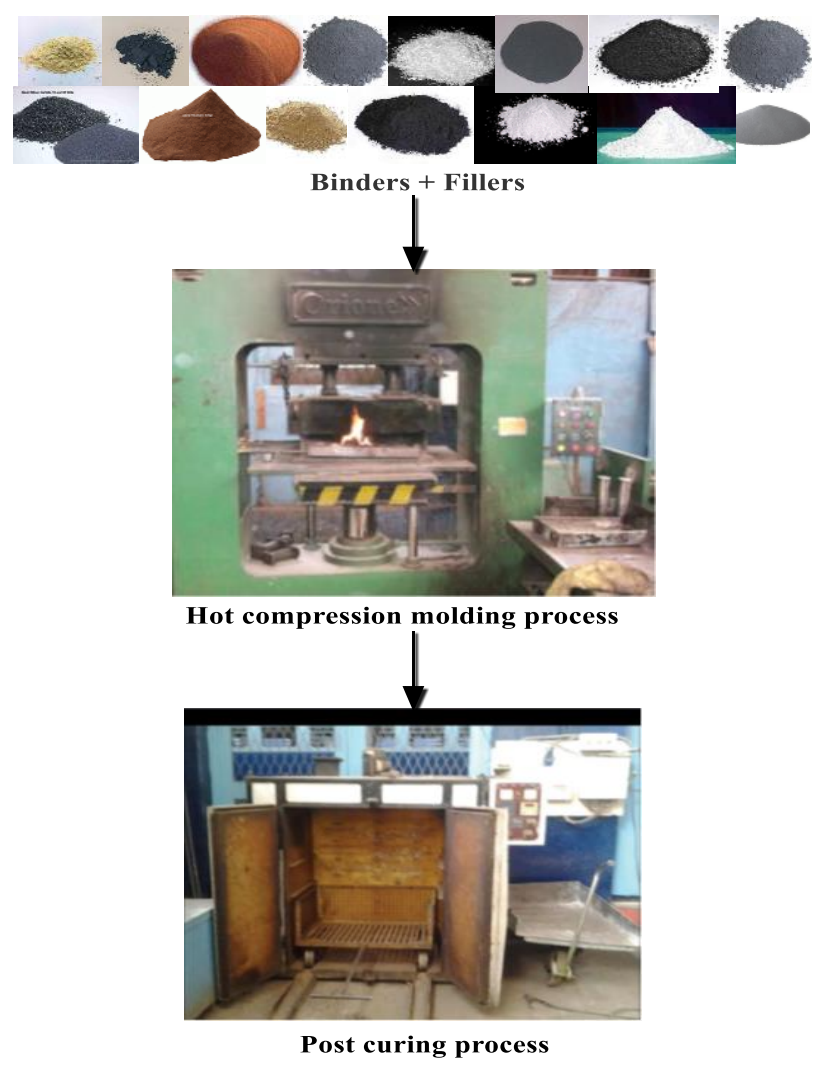

Figure 1. Process Chart for the Fabrication of PF based Hybrid Composites.

2.2.2. Characterization of Phenol Formaldehyde Composites: The experimental density of multi phased PF composites were determined by Archimedes principle using Sartorius make (Model - BSA224S-CW) densometer. The weight of the sample in air was noted and then immersed in distilled water at room temperature, a small holder was utilized to ensure complete sink of the sample and density was determined. The hardness was determined by Barcol impresser (Make - VERTEX). Hardness test was investigated as per the standard procedure using Barcol impresser. This test characterizes the indentation hardness through the depth of penetration of an 
indenter, loaded on a material sample and compared to the penetration in a reference material. Barcol hardness testing is a method of measuring the hardness of reinforced and non-reinforced rigid plastics. The hardness value is arrived at by assessing the plastic materials resistance to being penetrated by indenter. The specimen is placed under the indenter of the Barcol hardness tester and a uniform pressure is applied to the specimen until the dial indicator reaches maximum value. Later the depth of penetration is converted in to absolute Barcol numbers. The compressive and flexural properties were determined on Universal Testing Machine (Make - JJ Lloyds, London, UK, capacity $1-20 \mathrm{kN}$ ). The test (specimen size $=25 \mathrm{~mm}$ length and $12.5 \mathrm{~mm}$ diameter cylindrical pin, speed $2 \mathrm{~mm} / \mathrm{min}$, and load range of $10 \mathrm{kN}$ ) was carried out using Kalpak universal testing machine (Model KIC, serial number 121101) according to ASTM D 3410. Flexure test were carried out by changing the jaws of the set up and the specimen acts as simply supported beam subjected to point load at the middle by considering span length of $50 \mathrm{~mm}$. The flexural strength and flexural modulus were determined at the rate of $2 \mathrm{~mm} / \mathrm{min}$ as per ASTM D 790 .

2.2.3. Microstructure of Phenol Formaldehyde Composites: The surface morphologies of the selected PF based multiphase composite specimens were studied by a scanning electron microscope (SEM) (JSM-6510 LV, JEOL, Japan) with a maximum operating voltage of $20 \mathrm{kV}$. Specimens were mounted on aluminium stubs with carbon tape and sample-surface was coated with a thin gold layer by a sputtering unit prior to SEM measurements.

\section{Results}

\subsection{Microstructure of PF Based Hybrid Composites}

Figs. 2a, 2b, 2c, 2d, 2e and 2f show the microstructure using SEM of control composite sample (A1), molykote (A2), copper (A3), graphite (A4), graphite + molykote (A5) and graphite + antimony (A6) filled PF based hybrid composite, respectively. From Fig. 2a, it is clearly shown that the adhesion of the various binders, glass fiber and fillers (Table 2) with the PF matrix in the interfacial region is poor. The void spaces between various fillers, glass fiber with the binders and PF matrix are also shown, which indicate poor impregnation of fillers, glass fiber in the PF matrix. This poor impregnation and left out space between the constituents increased the void percentage in the A1 composite.

Figs. $2 \mathrm{~b}$ and $2 \mathrm{c}$ show photomicrographs of the $\mathrm{MC}$ and $\mathrm{Cu}$ filled $\mathrm{PF}$ based hybrid composites respectively. It can be seen from the corresponding figures that the $\mathrm{MC}$ and $\mathrm{Cu}$ particles and other fillers including short glass fibers were closely embedded in PF matrix with other binding materials and at some regions micro spaces (comparatively less than the former) exist at the interfacial province between the fillers and the matrix, which resulted in good filler-filler and matrix interaction. Lower voids and good bonding strength between fillers and binders enhanced the mechanical properties of the PF based MC and CU filled composites (A2 and A3) which are discussed in details in the subsequent sections.

Figs. 2d and 2e show photomicrographs of the $\mathrm{Gr}$ and $\mathrm{Gr}+\mathrm{MC}$ filled $\mathrm{PF}$ based hybrid composites respectively. More voids, poor dispersion of various fillers and bunching of glass fibers are the features that can be seen from Fig. $2 d$ for Gr filled PF based hybrid composite (A4). However, in case of combined fillers inclusion (sample A5) i.e., $\mathrm{Gr}+\mathrm{MC}$ filled PF based hybrid composite more or less uniform dispersion and directional orientation of glass fibers, various fillers were distributed uniformly and good interfacial adhesion between fillers, fibers with PF matrix can be seen from Fig. 2e.

Fig. 2f shows microstructure of PF based hybrid composite where in $\mathrm{Gr}$ and antimony fillers were included (A6). Non uniform distribution of fillers and more empty spaces left at various regions are observed in Fig. 2f. The void space between fillers and binders is more and hence increased the total void percentage in the final composite (A6). Poor bonding, non-uniform dispersion of fillers within binders and very poor bonding between fillers and binders may be the possible reasons for poor mechanical performance of the hybrid composite (A6) and these mechanical performance data are discussed in sections 3.2 to 3.5 . 

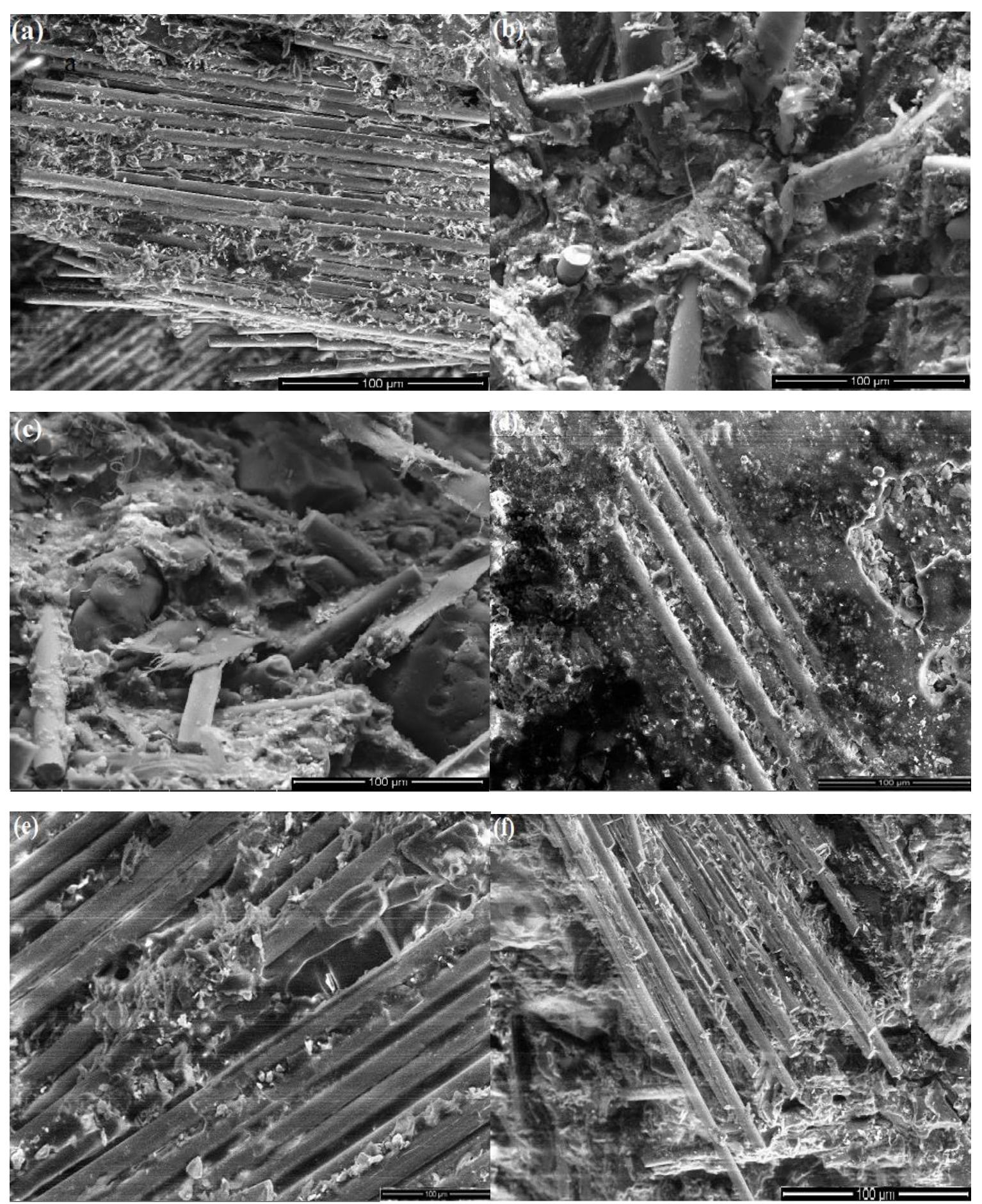

Figure 2. Microstructure of PF based Hybrid Composites: (a) Control PF composites (A1), b) MC filled PF (A2), c) Cu filled PF (A3), d) Gr filled PF (A4), e) $\mathrm{Gr}+\mathrm{MC}$ filled PF (a5), f) Gr + Antimony filled PF (A6).

\subsection{Density}

It is one of the primary characteristics of the polymer composites and majorly depends upon the relative proportion of the matrix and reinforcing elements and their respective density. Agarwal and Broutman [28] have obtained the theoretical density $\left(\rho_{c t}\right)$ of composite materials by using the following equation (1)

$$
\rho_{c t}=\frac{1}{\left\{\left(\frac{w_{f}}{\rho_{f}}\right)+\left(\frac{w_{m}}{\rho_{m}}\right)\right\}}
$$


where ' $w$ ' is the weight fraction and ' $\rho$ ' is the density of the corresponding materials. The suffixes ' $f$ ' denotes the filler/reinforcement element and ' $m$ ' represents the matrix respectively in a composite with unit filler/reinforcement. However, the present investigation involves eight different types of binders as matrix material and nine various ingredients as filler materials. Hence the above equation (1) has been tailored as follows.

$$
\rho_{c t}=\frac{1}{\left\{\left(\frac{w_{f_{1}}}{\rho_{f_{1}}}+\frac{w_{f_{2}}}{\rho_{f_{2}}}+\ldots \ldots \ldots \ldots .+\frac{w_{f_{9}}}{\rho_{f_{9}}}\right)+\left(\frac{w_{m_{1}}}{\rho_{m_{1}}}+\frac{w_{m_{2}}}{\rho_{m_{2}}}+\ldots \ldots \ldots \ldots+\frac{w_{m_{8}}}{\rho_{m_{8}}}\right)\right\}}
$$

where the suffix $f_{1}, f_{2} \ldots f_{9}$ denotes the nine various fillers and $\mathrm{m}_{1}, \mathrm{~m}_{2} \ldots \mathrm{m}_{8}$ stands for eight various binding elements as matrix material. The actual densities ( $\rho c a)$ of the prepared composites are determined by Archimedes principle in accordance with ASTM standard as mentioned in Table 3. The voids $(v)$ present in the prepared composites is calculated by using the following equation

$$
v=\frac{\rho_{c t}-\rho_{c a}}{\rho_{c t}}
$$

Table 4 presents the theoretical and experimentally measured densities along with the corresponding voids in the PF based hybrid composites. Reduction of fire clay to 5 wt. $\%$ from 10 wt. \% and inclusion of Cu by 5 wt. \% (A3) in PF composite has escalated the density by $17.8 \%$ compared with that of reference composite (without fillers A1). This is due to the density of $\mathrm{Cu}$, found to be the highest among the selected filler in the study group. Molybdenum disulphide (MC) filled PF composite (A2) exhibited slightly higher density by $7.9 \%$ compared to A1 composite and lower density by $8.37 \%$ compared to A3 composite. This is attributed to the reduced density of $\mathrm{MC}$.

\begin{tabular}{|c|c|c|c|c|c|c|c|}
\hline \multirow{2}{*}{ Property } & \multirow{2}{*}{$\begin{array}{c}\text { ASTM } \\
\text { Test }\end{array}$} & \multicolumn{6}{|c|}{ Phenol Formaldehyde composites } \\
\hline & & A1 & A2 & A3 & A4 & A5 & A6 \\
\hline $\begin{array}{l}\text { Density }\left(\mathrm{g} / \mathrm{cm}^{3}\right) \text {, } \\
\text { theoretical }\end{array}$ & $\begin{array}{l}\text { Rule of } \\
\text { mixture }\end{array}$ & 1.63 & 1.72 & 1.90 & 1.62 & 1.68 & 1.69 \\
\hline Density $\left(\mathrm{g} / \mathrm{cm}^{3}\right)$ & D 792 & 1.52 & 1.64 & 1.79 & 1.52 & 1.62 & 1.58 \\
\hline Voids $(\%)$ & ------ & 6.74 & 4.65 & 5.78 & 6.17 & 3.57 & 6.50 \\
\hline Barcol hardness number & D 2583 & 27 & 36 & 35 & 30 & 40 & 38 \\
\hline $\begin{array}{l}\text { Compressive strength } \\
\text { (MPa) }\end{array}$ & & 14.37 & 26.11 & 21.05 & 22.92 & 34.84 & 19.32 \\
\hline $\begin{array}{l}\text { Compressive modulus } \\
(\mathrm{MPa})\end{array}$ & D 3410 & 94.68 & 190.42 & 140.86 & 158.94 & 242.57 & 146.35 \\
\hline $\begin{array}{l}\text { Flexural strength } \\
(\mathrm{MPa})\end{array}$ & & 14.55 & 20.59 & 19.87 & 21.54 & 25.34 & 16.86 \\
\hline $\begin{array}{l}\text { Flexural modulus } \\
(\mathrm{MPa})\end{array}$ & D 790 & 58.99 & 80.58 & 77.22 & 84.52 & 100.55 & 63.42 \\
\hline
\end{tabular}

Table 4. Mechanical properties of phenol formaldehyde hybrid composites.

The measured density of hybrid composite with Gr and MC (A5) in PF demonstrated the density of $1.6 \mathrm{~g} / \mathrm{cm}^{3}$ which is less by $10.5 \%$ compared with A3 composite (Fig. 2). This is due to reduced density of $\mathrm{Gr}$ with $2.5 \mathrm{wt}$. \% content in the composite. Graphite and antimony filled PF (A6) composite demonstrated reduced density by $11.7 \%$ compared to $\mathrm{Cu}$ filled PF (A3) composite. This is due to the inherent density property exhibited by the $\mathrm{Gr}$ and antimony fillers compared to that of $\mathrm{Cu}$ filler. Further, Gr (5 wt. \%) filled PF composite (A4) and A1 composite demonstrated the equivalent density. This is due to the replacement of $5 \mathrm{wt}$ \% of fire clay by Gr, and these materials possess density values closer to each other. Further, it may be noted that the theoretical density of the composite deduced by the equation (2) are slightly higher than the experimentally measured 
value. This is attributed to the presence of voids in the composites. The presence of voids depends upon the packing factor of the filler and matrix materials. The shape and size of the particulates plays a vital role on the packing factor. Particulates with higher size and irregular geometries results in lower packing factor, thus leading to increase in void contents. The reference PF composite (A1) possess maximum voids of $6.74 \%$ in the study group. The presence of $10 \mathrm{wt}$. \% fire clay with irregular geometry and having average particle size of $230 \mu \mathrm{m}$, has reduced the packing factor with increase in void fraction. The irregular geometry and the larger particle size have increased the distance between the consecutive particles, thus providing more space for formation of voids. PF composite with graphite and antimony (A6) showed $6.5 \%$ of void. The Gr and antimony used in the investigation has fine and coarse flaky structure with average particle size of 50 and $135 \mu \mathrm{m}$ respectively, resulting in increased void fraction of the composite. Filler like $\mathrm{Gr}$ and $\mathrm{MC}$ in PF composite (A5) possess lowest void percentage $(3.57 \%)$ in the study group. The particle sizes are comparatively lower and this has reduced the space for void formation and thus resulted in lower void fraction.

The PF based hybrid composites had calculated density values based on the actual density of the micron sized fillers used. There was variation of percentage voids from 3.57 to 6.74 between the PF based hybrid composites (Table 4). PF based composite with MC and Gr showed that there was marginal difference in density values. It can be also concluded that the PF based composite manufacturing procedure has meticulously performed, which is of a great importance to obtain the hybrid composites having homogeneous performance in the study group.

\subsection{Hardness}

The hardness of the PF based hybrid composites are listed in Table 4 and in the form of bar chart shown in Fig. 3. It is evident from the Table 4 and Fig. 3 that the PF composite with Gr and MC has demonstrated better hardness in the study group. This is attributed to lower voids and improved adhesion of filler-filler with the PF matrix material. Suresha et al. [29] observed as compared to C-E, graphite filled C-E posses higher density, hardness and tensile strength. Further, $\mathrm{MC}$ and antimony has higher average molecular weight followed by $\mathrm{Cu}$ and $\mathrm{Gr}$ in the study group. Also antimony possesses higher hardness followed by $\mathrm{Cu}, \mathrm{Gr}$ and $\mathrm{MC}$. The presence of these fillers enhanced the hardness of the PF based hybrid composite comparatively.

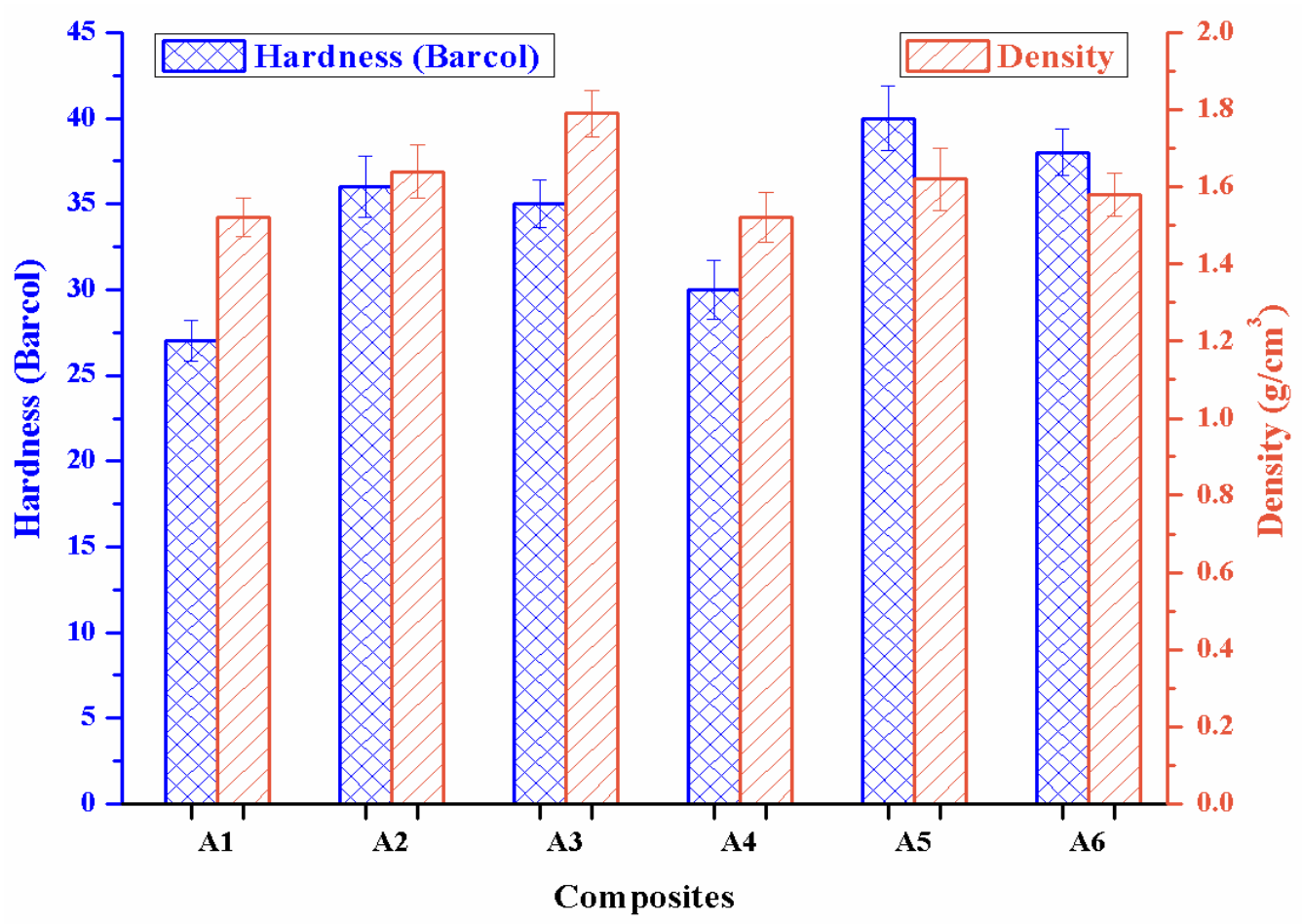

Figure 3. Hardness (Barcol) and density of Phenol formaldehyde-based multihpase composites. 


\subsection{Flexural Strength and Flexural Modulus of PF Based Composite}

The average flexural strength $\left(\sigma_{\mathrm{f}}\right)$ and flexural modulus $\left(\mathrm{E}_{\mathrm{f}}\right)$ evaluated from three-point bend tests for PF based hybrid composite specimens are shown in Fig. 4. It is seen that $\sigma_{\mathrm{f}}$ increases with different $\mathrm{MC}, \mathrm{Cu}$ and $\mathrm{Gr}$ fillers except combined filler loading ( $\mathrm{MC}+$ antimony) in the control sample (A1). The rate of increase of $\sigma_{\mathrm{f}}$ is different for all the fillers studied, indicating the type, shape and size of the filler importance. The flexural strength value for the control sample is 14.55 MPa, while it increases to a value of $21.54 \mathrm{MPa}$ for PF based composite with $5 \mathrm{wt}$. \% Gr content. On the other hand, contrary to the increase in $\sigma_{\mathrm{f}}$ value, the strength is found to decrease with the incorporation of graphite and antimony fillers (16.86 MPa, Specimen A6). The minimum value of $\mathrm{E}_{\mathrm{f}}$ observed for the unfilled $\mathrm{PF}$ composite specimen is $58.99 \mathrm{MPa}$ and the maximum $\mathrm{E}_{\mathrm{f}}$ value obtained for PF based multiphase composite specimen of $2.5 \mathrm{wt} \% \mathrm{MC}+2.5 \mathrm{wt}$ \% $\mathrm{Gr}$ is $100.55 \mathrm{MPa}$. Therefore, the highest increase in obtained herein $\mathrm{E}_{\mathrm{f}}$ is $70 \%$. Improvement in bending strength of Phenol formaldehyde resin/graphite composite was found by Yin et al. [31].

Among all the filler-filled PF based composites, the lower $\sigma_{\mathrm{f}}$ of the PF based composite is with Gr and antimony filled ones (A6). It was noticed that flexural strength/modulus was increased for smaller particle size (A2 - A5) and the decreases for the larger particle size (A6). This could be due to a number of reasons, such as weak interfacial bonding at $\mathrm{Gr}$ and antimony particles with PF matrix interfaces, agglomeration of micron sized particles, less surface area of antimony particles due to bigger particle size, process-related defects such as porosity and so on. The change in $\sigma_{\mathrm{f}}$ is also controlled by the particles size of the filler along with molecular weight, flexibility and surface properties of filler and matrix, thus, bigger (120-150 $\mu \mathrm{m})$ antimony particles filled PF leads to more voids, lesser filler-matrix interaction, thereby showing lower strength as well as modulus. Further, it is worth mentioning that $\sigma_{\mathrm{f}}$ of a material is the maximum stress exhibited by it under deflection. Under the deflection processes, the position and movement of filler aggregates, matrix molecules and develop pores during fabrication inside the material may affect the resulting interaction among PF-PF molecules, filler-filler aggregates and PF/Filler molecules.

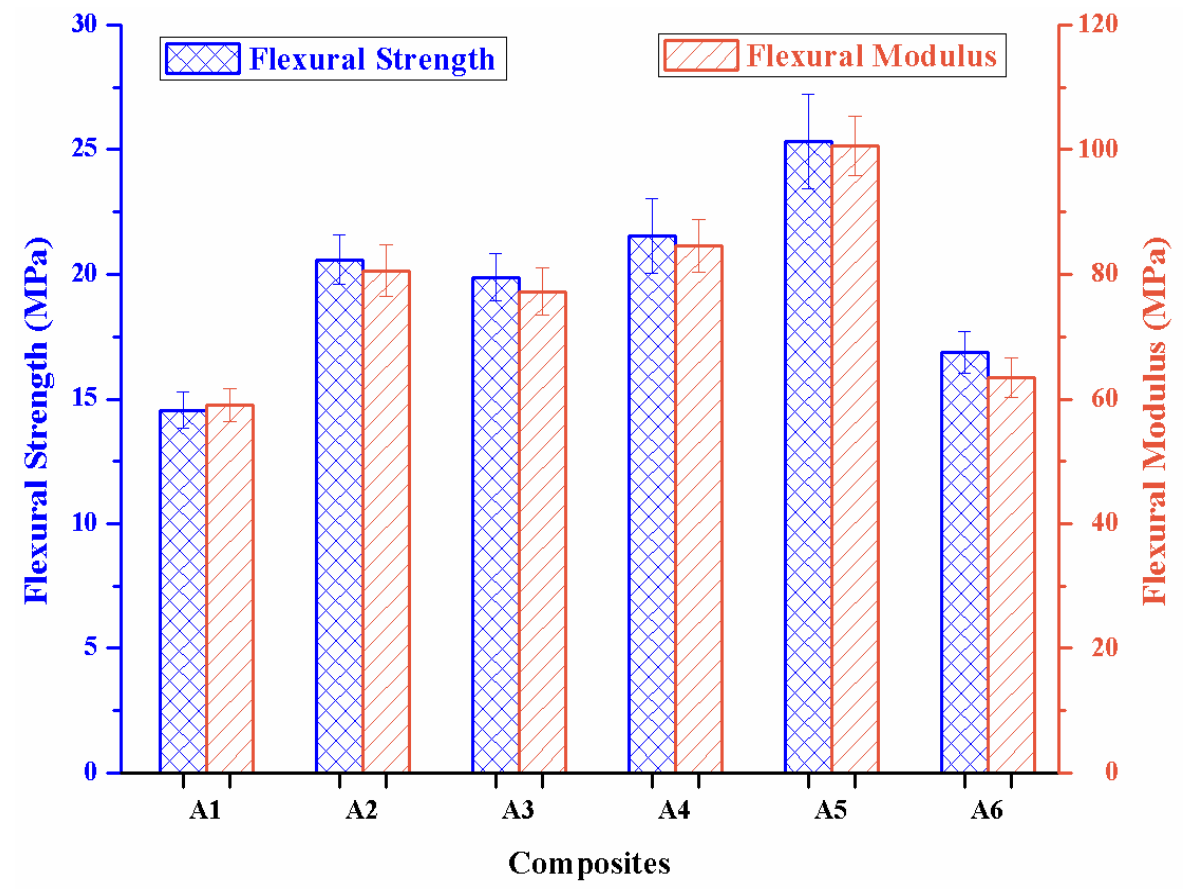

Figure 4. Flexural strength and modulus of PF based hybrid composites. 


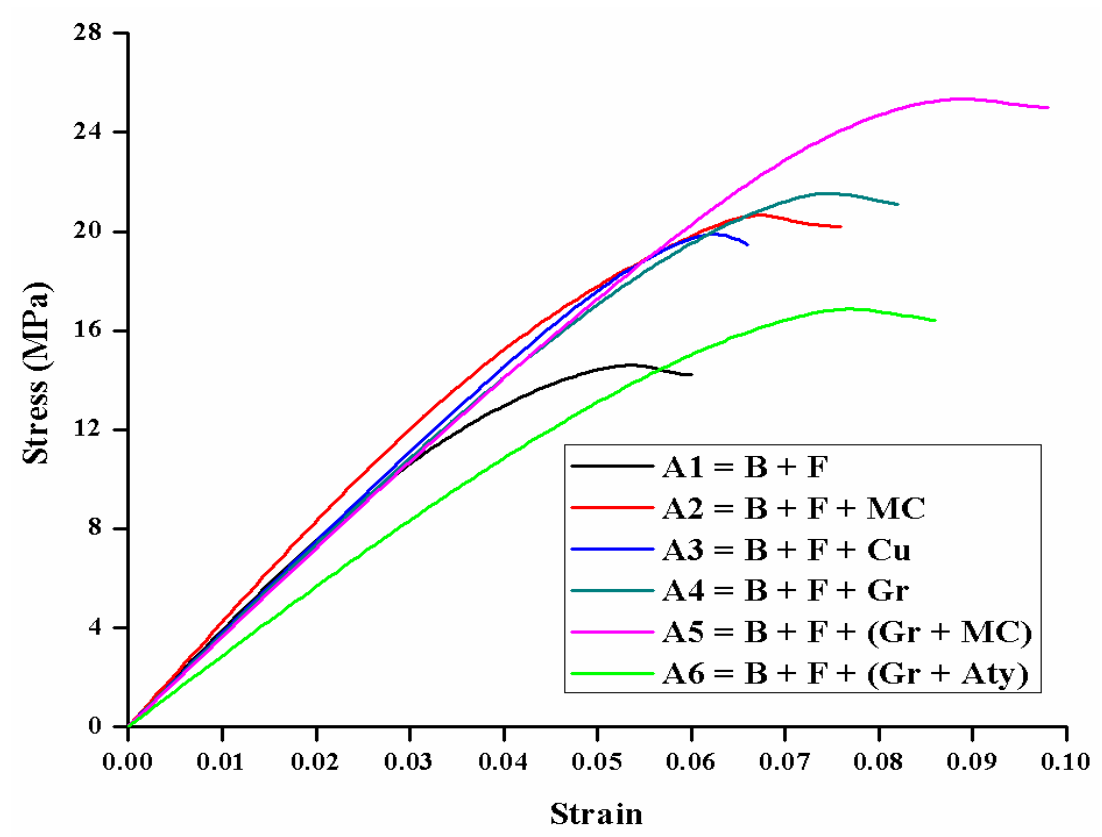

Figure 5. Stress versus Strain (flexure-mode) of phenol formaldehyde-based multiphase composites.

Dwindling of interaction due to above mentioned facts is assumed to reduce the $\sigma_{\mathrm{f}}$ of the PF based composites with different compounded filler loading. Moreover, the adsorption of the antimony filler limited wettability in PF matrix phase may result in poor interface adhesion of Gr particles to PF matrix, and inefficient stress-transfer between the particle-matrix interface occurs as long as the load is applied.

The smaller particle size fillers ( $\mathrm{MC}$ and $\mathrm{Cu}$ ) tends to agglomerate and hence reduced the flexural strain values by restricting the mobility of matrix chains, which was also supported by the trend of variation in strain at break of PF based composite (A1) filled with MC (A2) and Cu (A3) as shown in Fig. 5. Fig. 5 represents the variation in flexural strain at break of different filler reinforced PF based composite systems.

\subsection{Compressive Strength and Modulus of PF Based Composite}

The compressive strength of reference PF based composite (A1) and filler reinforced PF based composite systems (A2 - A6) are shown in Fig. 6. Particulate reinforced PF based composites showed higher compressive strength than the unfilled PF composite and when combination of MC and Gr were included to the PF composite (A5), compression strength significantly increased. The compressive strength of A5 composite was found to increase by $142 \%$ in comparison with A1 composite and $82 \%$ with A2 composite. Further, the MC (A2) and Gr (A4) reinforced $\mathrm{PF}$ composite compressive strength is higher than $\mathrm{Cu}$ (A3) reinforced but lower than that of combined hybrid filler reinforced PF composite (A5). The increase in compressive strength of hybrid PF composite is because of graphite filler content. The variation of compressive strength of $\mathrm{MC} / \mathrm{Gr}$ and $\mathrm{Gr} /$ antimony particulate reinforced hybrid PF composites are also shown in Fig. 6. It is observed that the MC reinforced PF composite with $\mathrm{Gr}$ filler addition is exhibiting higher compressive strength. Additionally, compressive strength was found marginal increase (34\%) for hybrid particulates ( $\mathrm{Gr}$ and antimony) in PF based composite (A6), possibly due to poor quality of the composite, formation of air pockets which may be due to their higher surface energy to adhere among themselves and to larger inter-particle distance between fillers, in which case matrix breakage becomes the prominent failure mechanism. Gautam and Kar [31] found that the composite slabs with filler weight percentage of 35/5/3/exfoliated graphite/carbon black/graphite powder, offered in-plane and trough-plane electrical conductivities of 374.42 and $97.32 \mathrm{~S} / \mathrm{cm}$, bulk density $1.58 \mathrm{~g} / \mathrm{cm}^{3}$, compressive strength $70.43 \mathrm{MPa}$, flexural strength $61.82 \mathrm{MPa}$, storage modulus 10.25 GPa and microhardness $73.23 \mathrm{HV}$. 


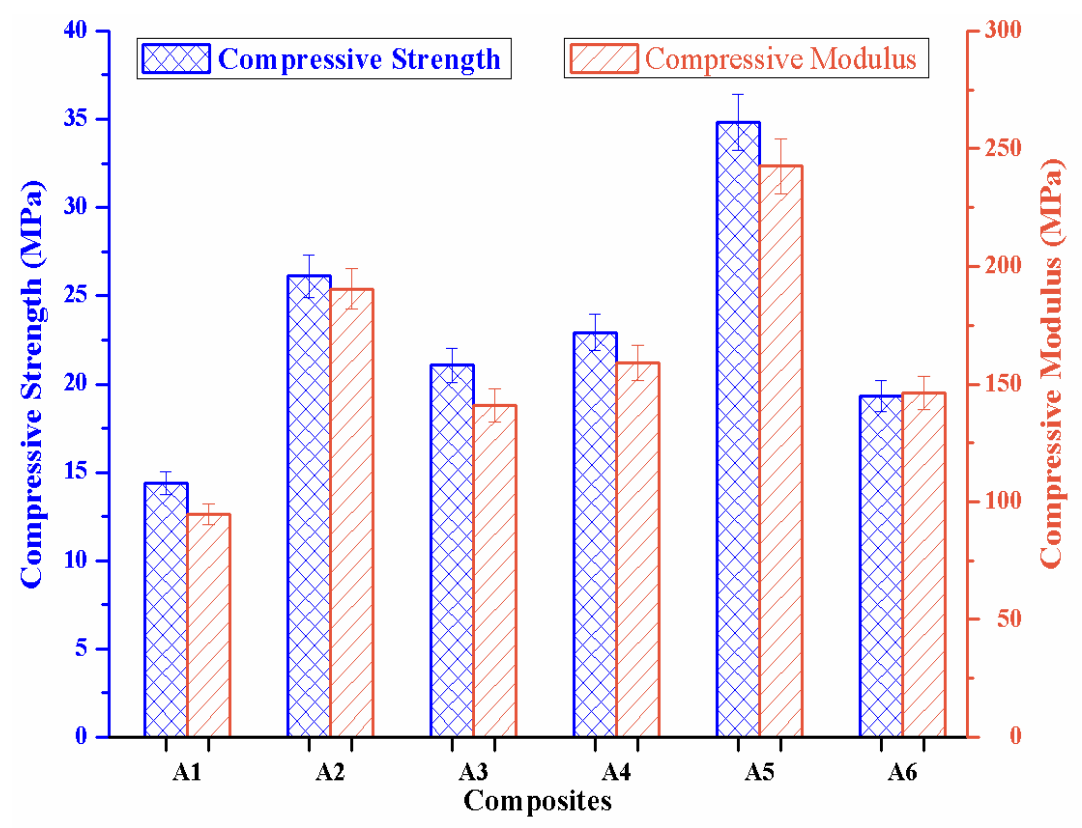

Figure 6. Compression Strength and Modulus of PF based Hybrid Composites.

Influence of different filler inclusion on compressive modulus of PF based composites are as shown in Fig. 6. The modulus of the PF based composite (A1) was increased by $101 \%$ due to the incorporation of MC filler within the PF matrix (A2). Further, addition of $2.5 \mathrm{wt}$. \% Gr particles to A2 composite, the result was quite interesting and the compressive modulus was significantly enhanced by $156 \%$ as compared to A1 composite. There was an improvement of $68 \%$ in the modulus for the addition of Gr filler into the PF matrix was recorded (A4). The modulus of A4 composite was decreased by $13 \%$ with further addition of $2.5 \mathrm{wt} . \%$ of antimony filler (A6). These results thus proves that the compressive strength and modulus to the PF based composite (A1) was improved due to the addition of $\mathrm{MC}, \mathrm{Cu}, \mathrm{Gr}$ and their hybrid particles within the PF matrix.

The rule of mixture equation (4) was applied to randomly distributed particulate/short fiber reinforced polymer composite materials;

$$
E_{\text {Comp }}=K \times\left(E_{m} \times w_{m}+E_{p} \times w_{p}\right)
$$

where $E_{C o m p}=$ modulus of the polymer matrix composite, $E_{m}, E_{p}$ are the modulus of the matrix and particulate/fiber materials; $w_{m}, w_{p}$ are the weight fraction of matrix and particulates/fibers. $K$ is the constant called as reinforcing material efficiency parameter. However, filler loading constitutes to 40 wt. \% and is constant for all the PF composites, and hence equation (4) reduces to equation (5) as below:

$$
E_{\text {Comp }}=K \times\left(E_{p} \times w_{p}\right)
$$

Further the values $\mathrm{K}$ was determined using equation (5) and are noted in the Table 5. Flexural modulus of $\mathrm{PF}=7.5 \mathrm{GPa}$, Molykote $=9.31 \mathrm{GPa}$ and Graphite $=16.8 \mathrm{GPa}$ were considered [32] for calculation.

Table 5. $K$ value of PF composites.

\begin{tabular}{|c|c|c|}
\hline Composites & $\begin{array}{c}\text { Flexural modulus of } \\
\text { composites }\left(\boldsymbol{E}_{\text {Comp }}\right) \text { in MPa }\end{array}$ & $\boldsymbol{K}$ \\
\hline A1 & 58.99 & 0.0131 \\
\hline A2 & 80.58 & 0.0175 \\
\hline A3 & 77.22 & NA \\
\hline A4 & 84.52 & 0.0170 \\
\hline A5 & 100.55 & 0.0210 \\
\hline A6 & 63.42 & NA \\
\hline
\end{tabular}


Fig. 6 shows that the values of $K$ have the close proximity for the $\mathrm{MC}$ and $\mathrm{MC}+\mathrm{Gr}$ reinforced PF composites (A2 and A5). This value is in higher side for the MC filler and intermediate values for the $\mathrm{Cu}$ and $\mathrm{Gr}$ reinforced $\mathrm{PF}$ composite materials (Table 5).

\section{Conclusions}

Combined effect of filler-filler interaction on mechanical properties of phenol formaldehyde based hybrid composite systems were investigated and the following conclusions can be drawn from experimental results:

- $\quad$ The microstructure observed with SEM, revealed that fillers like molybdenum disulphide and copper strongly improved the adhesion and compatibility with other fillers as well as with various binders in PF based hybrid composites.

- Molykote/copper/graphite loading influenced the density and hardness of PF based composite systems (A2, A3, A4 and A5) and they showed increased tendency as compared with reference PF composite (Sample A1) and hybrid filler (graphite + antimony; A6) loaded composite systems. Samples of A3 (5 wt. \% Cu) showed highest density whereas A5 ( $\mathrm{Gr}+$ MC) showed the highest hardness.

- $\quad$ The $\mathrm{MC} / \mathrm{Cu} / \mathrm{Gr}$ filled PF based hybrid composites showed good compressive and flexural strengths as well as modulus compared to the control sample (A1).

- The hybridization of $\mathrm{MC}+\mathrm{Gr}$ in $\mathrm{PF}$ based composite increased the mechanical properties, which was highest for $\mathrm{B}+\mathrm{F}+(\mathrm{Gr}+\mathrm{MC}) \mathrm{PF}$ based hybrid composite (A5) among all the PF based composites studied in the group.

\section{Conflict of Interest}

Authors are hereby making humble note about not making complete disclosure of formulation of Materials system and methods followed to fabricate Composite Brake Block (CBB) specimens. Since, it is treated as confidential matter by South Western Railway, Office of the CWM, Central workshop, Mysore South, Karnataka. However, with the consent of South Western Railway authority, authors bring out the sufficient details required for technical understanding of present investigation and for publication.

\section{Acknowledgments}

The authors express sincere thanks to Mr. B. Sasikumaran Nair, AWM, and Mr. K.B. Anantha Kumar, Senior Section Engineer, Composite Brake Block (CBB) section, South Western Railway Workshop, Mysore division, Karnataka, India for their kind assistance in the fabrication of multiphase composites.

\section{References}

[1] A.M. Riley et al., Factors affecting the impact properties of mineral filled polypropylene, Plast. Rub. Proc. Appl. 14 (1990) 85-93.

[2] P.W.R. Beaumont, Fracture mechanics in fibrous composites, in: R.A. Smith (Eds.), Fracture Mechanics: Current Status, Future Prospects, Oxford, Pergamon Press, 1979, pp. 211-233.

[3] J. Weizhou, L.Youzhi, Q. Guisheng, Studies on mechanical properties of epoxy composites filled with the grafted particles PGMA/A12O3, Compos. Sci. Technol. 69 (2009) 391-395.

[4] S.Y. Fu et al., Effects of particle size particle/matrix interface adhesion and particle loading on mechanical properties of particulate-polymer composites, Composites Part B: Engineering. 39(6) (2008) 933-961. 
[5] A. Knop, L.A. Pilato, Phenolic resins: chemistry, applications and performance, Berlin Heidelberg, Springer-Verlag, 1985.

[6] J. Wang, H. Jiang, N. Jiang, Study on the pyrolysis of phenol-formaldehyde (PF) resin and modified PF resin, Thermochimica Acta. 496(1-2) (2009) 136-142.

[7] O.L. Ferguson, R.G. Shaver, Syntactic Foams of hollow carbon microspheres in resin matrix, J. Cellular Plastics. 6 (1970) 125.

[8] S. Wang, S. Adanur, B.R. Jang, Mechanical and thermo-mechanical failure mechanism analysis of fiber/filler reinforced phenolic matrix composites, Composites Part B: Engineering. 28(3) (1997) 215-231.

[9] G. Yi, F. Yan, Mechanical and tribological properties of phenolic resin based friction composites filled with several inorganic fillers, Wear. 262 (2007) 121-126.

[10] R.D. Patton et al., Ablation, mechanical and thermal conductivity properties of vapor grown carbon fibre/phenolic matrix composites, Composites Part A: Applied Science and Manufacturing. 33(2) (2002) 243-251.

[11] K. Haraguchi, Y. Usami, Y. Ono, The preparation and characterization of hybrid materials composed of phenolic resin and silica, Journal of Materials Science. 33 (1998) 3337-3344.

[12] M.D. Li et al., Electrical and flexural properties of copper and graphite filled phenolic resin composites, Advanced Materials Research. 418 (2012) 1044-1047.

[13] L.E. Nielsen, Mechanical properties of particulate-filled systems, J. Composite Materials. 1 (1967) 100.

[14] B. Suresha et al., Mechanical and three- body abrasive wear behavior of carbon-epoxy composite with and without graphite filler, Journal of Composite Materials. 44(21) (2010) 2509-2519.

[15] N. Srikanth et al., Mechanical, thermal and ablative properties of zirconia, CNT modified carbon/phenolic composites, Composites Science and Technology. 80 (2013) 1-7.

[16] P.V. Gurunath, J. Bijwe, Friction and wear studies on brake-pad materials based on newly developed resin, Wear. 263 (2007) 1212-1219.

[17] C. Tang, Y. Lu, Combinatorial screening of ingredients for steel wool base semi-metallic and aramid pulp based non-asbestos organic brake material, Journal of Reinforced Plastics and Composites. 23(1) (2004) 51-63.

[18] K. Kumaresan et al., Dynamic mechanical analysis and three-body wear of carbon-epoxy composite filled with SiC particles, Journal of Reinforced Plastics and Composites. 31(21) (2012) 1435-1448.

[19] M. Kumar, J. Bijwe, NAO friction materials with various metal powders: Tribological evaluation on full-scale inertia dynamometer, Wear. 269 (2010) 826-837.

[20] D. Chan, G.W. Stachowiak, Review of automotive brake friction materials, Proc. Inst. Mech. Eng.: Part D: J. Autom. Eng. 218(9) (2004) 953-966.

[21] J. Bijwe, M. Kumar, Optimization of steel wool contents in non-asbestos organic (NAO) friction composites for best combination of thermal conductivity and tribo-performance, Wear. 263 (2007) 1243-1248.

[22] M.A. Mohammed, Mechanical behavior for polymer matrix composite reinforced by copper powder, Nahrain University College of Engineering Journal (NUCEJ). 14(2) (2011) 160-176.

[23] A. Akinci, Mechanical and structural properties of polypropylene composites filled with graphite flakes, Archives of Materials Science and Engineering. 35(2) (2009) 91-94. 
[24] D. Li et al., Effect of several modifiers on the mechanical and tribological properties of phenol formaldehyde resin, High Performance Polymers. (2017).

[25] P. Cai, T. Wang, Q. Wang, Effect of several solid lubricants on the mechanical and tribological properties of phenolic resin based composites, Polymer Composites. 36(12) (2015) 2203-2211.

[26] S. Shi et al., Degradation in compressive strength of silica/phenolic composites subjected to thermal and mechanical loading, Journal of Reinforced Plastics and Composites. 35(7) (2016) 579-588.

[27] South Western Railway, Central workshop, Mysore South, Karnataka, Materials amendment 2 for $\mathrm{CBB}, 2012$

[28] B.D. Agarwal, L.J. Broutman, Analysis and performance of fiber composites, 3rd ed., New York, John Wiley and Sons, 1990, pp. 440-441.

[29] B. Suresha et al., Mechanical and three-body abrasive wear behavior of carbon-epoxy composite with and without graphite filler, Journal of Composite Materials. 44(21) (2010) 2509-2519.

[30] Q. Yin et al., Study on the electrical and mechanical properties of phenol formaldehyde resin/graphite composite for bipolar plate, Journal of Power Sources. 165(2) (2007) 717-721.

[31] R.K. Gautam, K.K. Kar, Synergistic effects of carbon fillers of phenolic resin based composite bipolar plates on the performance of PEM fuel cell, Fuel Cells. 6(2) (2016) 179192.

[32] Available at: http://www.matweb.com/. 